changes that it shuts up its petals in the dampair which precedes rain, and is widely relied upon, before peculiarity is also possessed by other common wild flowers, such as the wood anemone, or wind flower, the frage and the chick weed even go so far as to half open African marigold, which closes its petals regularly at African marigold, which closes its petals regularly at nightfall, fails to

Not only the flowers, but also the leaves of some plants, give warnings of approaching change. Pliny fore a storm; and Virgil has described the signs of coming weather given by the leaves of the almond tree. The wild licorice plant (Abrus precatorius), the so-
called weather plant, is said to hang its leaves horizontally for a change, upward for fine weather, and drooping for rain. This fact was called attention to in 1892 ; but the Kew observers who have specially stuthe direct agency of light, heat, and moisture. In the United States it is a common saying that the leaves
of the sugar maple turn upside down before a storm. while the silver maple shows the white lining of its
leaf. In our own country, the wood sorrel, lime, poplar, sycamore, and plane trees vary the direction of their leaves with different conditions of the atmosphere. well-known saying which attempts to deter. mine the weather of the coming summer by the pri-
ority of the oak or ash in the development of leaf buds has probably no more foundation in fact than belongs to the natural characteristics of these trees. In this country the oak is usually in leaf before the ash, and in so moist a climate the early summer is more often wet than dry.

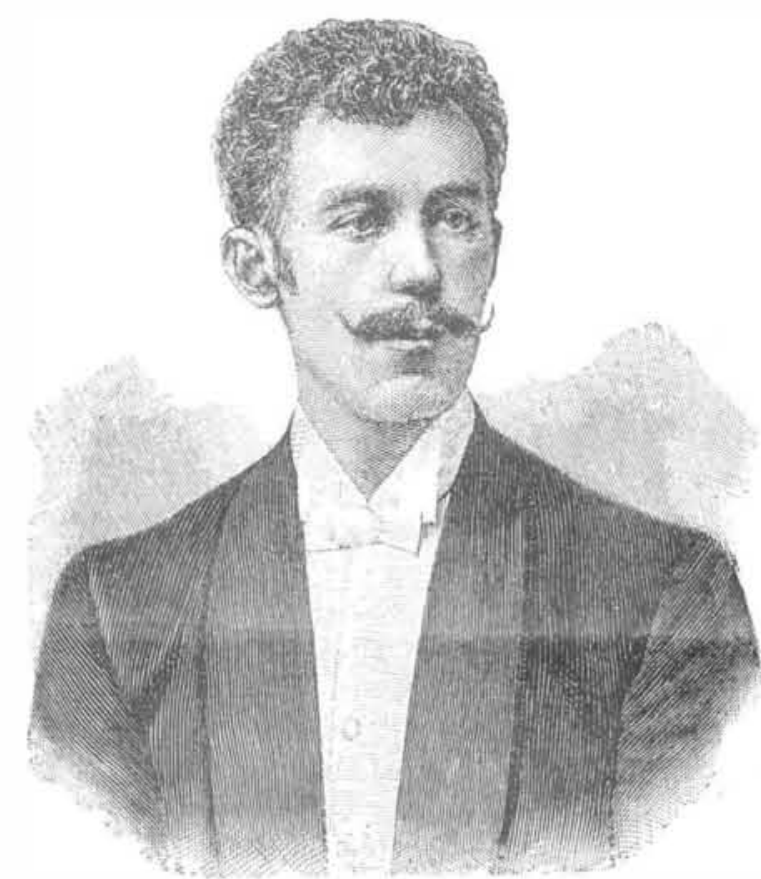

WILLY BURMESTER. of the storms which traverse these islands are of the one of the most prominent in the lists of violinists of cyclonic type, in which there is alwavs a well-defined his time.

distribution of atmospheric temperature and pressure. The front of an advancing cyclone is marked by effect upon the nervous system of man himself. It is not surprising that the lower animals should feel it flowers, and other odors, more apparent, and explain the habit of sniffing the air displayed by many animals before a storm. The excessive dampness of the atmosphere, by its influence on cutaneous perspiration, discomfort which so many of the fur and feather tribe betray during the passase of a cyclone across our are peculiarly affected by the humidity of the air. The Zuni Indians of New Mexico were wont to predict rain fromlthe appearance of the scalp locks captured from their enemies. The fur of animals, the moist skins of
toads and frogs, and the plumage of birds are very toads and frogs, and the plumage of birds are very
sensitive to small variations in the hygrometric state of the atmosphere.

Dampness has also a marked effect upon many vegetable tissues. If a beard of wild oat is fixed upon a amount of water vapor present in the atmosphere Pine cones can be used in a similar manner as natura hygrometers, closing up their scales in damp weather. stalks of plants are softened by damp, causing the plant mimosa exhibits increased irritability in the warm, moist air of a cyclone tront; and even the downy hairs of dandelions. thistles. and colt's foot contract
and expand under the ever varying influence of atmospheric vapor.

plants explanation of the movements of plants described alove. The plowinan's weather glass sensibility is thus accounted for; it tells us actual conditions, which, rightly understood, may be capable of interpretation as signifying changes to come.

After the cyclone front has passed away, the air be comes dry and bracing, and a feeling of exhilaration to sea ward, rooks and kites soar aloft in the air, insects float in the light breeze in search of honey dew, and plants expand their leaves boldly to the sun. The constorm are over.-Chambers's Journal.

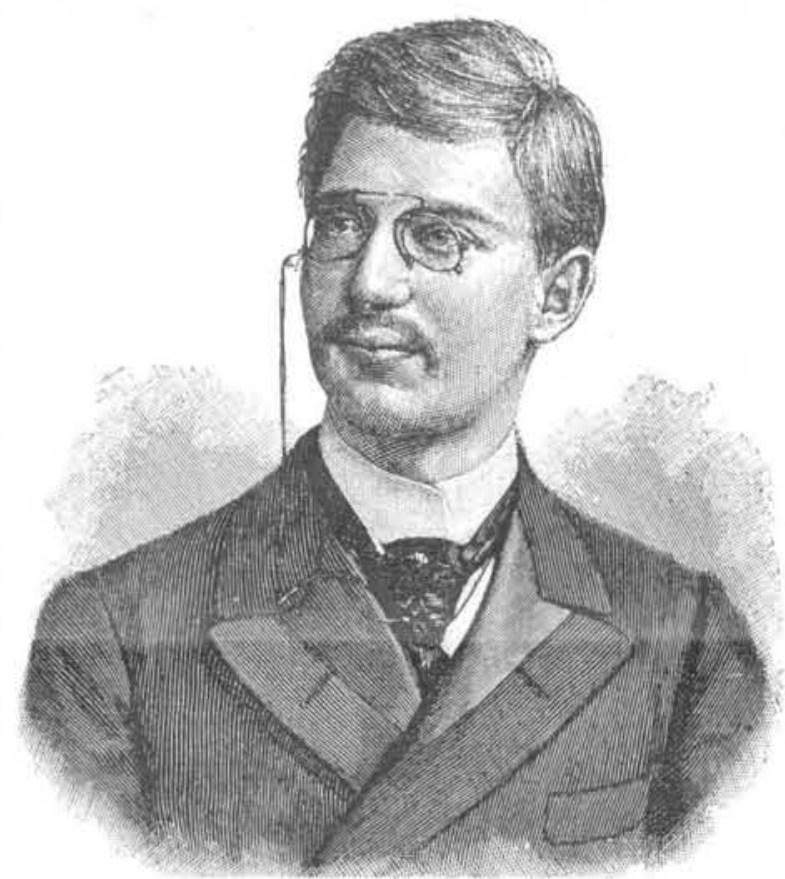

ALEXANDER PETSCHNIKOW.
WILLY BURMESTER AND ALEXANDER PETSCHNIKOW.

We publish herewith portraits (for which we ar and Alexander Petschnikow, two violinists who are When the former made his debut in Leipzig he ensation when he appeared in Berlin and Leipzig country and in Paris.

Willy Burmester was born in Hamburg, and when his own in which he soon gained a reputation as a
brilliant virtuoso who seemed to give promise of a deided and energetic individuality. His talent is rencludes music of every, consequently, his repertoire undertake to write a history of the violin virtuosi of Burmester; " so says our German cotemporary.
It is only lately that the Russian violinist, Alexander Petschnikow, has appeared in Germany as Burmester' the son of a simple Russian soldier, was born December 7, 1872, Russian style (January 8, 1873) at Jeletz, in the Imperial Opera Orchestra, Mr. Solotarenko, of the
Iiscovered the talent in a way to have it cultivated at the Moscow him eacher procured for him the loan of a very fine violin the celebrated Laub. owner of this hishly prized violin, which helped him o wonderful suecess on his musical tours. His
echnique is most perfect. His name will always be

\section{GROWTH OF POPULATION OF GREAT CITIES*}

By Elmer Lawrence Cortheli, D.Se.

IN 1886 and 1887 Mr. Rudolph Hering, civil engineer the problem of water supply and drainage of the city of Chicago, compiled some statistics and made a diagram
showing the curve of growth of populaticn of several cities in the United States. About the year 1890, for the
con purpose of presenting in a professional report on the several cities shown on Mr. Hering's diagram, the writer extended the diagram to a more recent date.
During the last year he has, by an extended correDuring the last year he has, by an extended correspondence, obtained the necessary information and has
plotted on a new diagram the curves of growth of pop$1,000,000$, inhabitants at the present time. These curves have been extended both backward and forward, as will be seen by an exanination of the diagram. Many interesting and instructive features are
presented by this comparison, and the value of the results thus presented graphically will be at once appre-
ciated by an examination of the diagran. ciated by an examination of the diagran.
The editor of London Engineering (to which this paper is primarily contributed and by which it is now eing published) suggested to the writer during the investigations that it would be still further instructive ally the comparison of density of population. Thi formation. The squares showing these densities are rom the latest census in each case and may be The information has been obtained from official
Then sources through the following correspondents, all of the author's requests for data and to whom he is figures:
. Mr. James Forrest. Secretary, Institution of Civi Corresponding Member of the American Society of
Civil Engineers, Hamburg, Germany; Mr. Ernest * From the proceedings of the American Association for the Advance-
ment of Aclence, vol, allv, 2895. ervatory. He took the first prize before leaving this
Pontzen, C. E., also Corresponding Member of the
American Society of Civil Engineers, Paris, France American Society of Civil Engineers, Paris, France to Russia, and Lieut. Henry I. Allen, naval attache of the United States Legation, St. Petersburg, Russia; Hon. Chas. Denby, United States Minister to China,
Pekin; Mr. John C. Trautwine and others in the United States

As each city has its peculiarities in history, growth take up each separately in order that the reader ully understand and appieciate the curves on the diagrams.

For the information of our readers who are not familiar with the peculiar geographical conditions of the population, the following data need to be given
order to have a full understanding of the subject. order to have a full understanding of the subject.
London within various boundaries :

Within the registrar-general's tables of mortal-

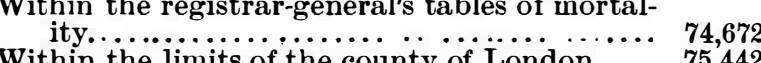

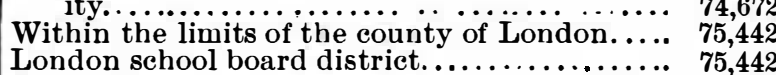
London school board district................... 75,442
City of London within the municipal and par-

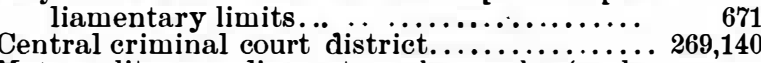
Central criminal court district................ 269,140
Metropolitan parliamentary boroughs (excluSame (including the City of London).............. 74.771 Metropolitan police district (not including the

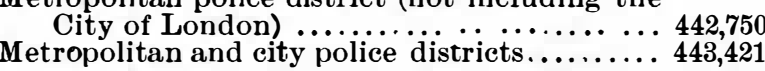
The metropolitan police district extends over a square miles-exclusive of the City of London. The population used in the curve of growth is that included in the registrar-general's area. It is almost
impossible in the case of .London, as well as that of other cities, to define the area of the metropolitan pop-
ulation, that is the population of the city itself and of the suburban districts which contain the population doing business in the city. The limits of London could be extended far beyond those of the registrargeneral, and with each extension a much different population would be found to exist. To compare, perhaps,
more favorably with the other cities and cover the metropolitan area, it seems proper to state that the population supplied by the London water companies tion is plotted on the diagram. 'In 1891 the population was $5,633,806$.

As to density of population, that of the Whitechapel district is taken as a maximum, being on the
357 acres included, at the rate of 132,000 per square mile. The average in the per square mile. NEW YORK.

The curve of this great city of the United States is in, teresting, first, by its comparison with its neighbor Philadelpbia. The curves show that they kept pace with each other very closely from the year 1700 to 1830 ,
when population in New York began to grow with has continued to do so up to the presof tinye, the ratio of increase being greater than that and Berlin. The density of the tenth ward, which is on the east side of the city between the Brooklyn
Bridge and Grand Street is greatest of anylin the world with the exception, perhaps of a certain district in the city of Prages, and sanitars district A, of the eleventh ward, has the greates density of any corresponding area of the world, and
twice that of Prague in 1893: It comprises about 320 acres and the density ranges from 600 to 1,000 inhabitants per acre, or an ! average of about 512,000 per
square mile; the greatest density being 640,000 per square mile.

In 1860 the area of Paris was considerably extended the population at that time nearly half a million. The density of the population is shown, first, by taking out the squares, or greens and woods, making the average on this basis, 121,300 per square mile and the area $22 \cdot 4$ square miles. The average of the entire city, ncluding the squares, etc. is 79,500 per square mile,
covering 31 square miles. Thecurve of, growth of Paris brings out several interesting and important historica points. For instance, the eity, as is well known, suf-
fered greatly during the latter part of the reign of Louis XVI and during the reign of terror, from 1774 to 1799 , during which period the population actually decreased. On the other hand, under the reign of Louis
XIV, 1643 to 1715 , and that of Louis XV, 1715 to 1754 , it greatly prospered and the growth in the latter pe-
riod is shown on the curve as having a regular inrod is shown on the curve as having a regular in
crease. From 1852 to 1870 the Emperor Louis Napofor Paris and its growth was very rapid by the Franco-Prussian war and the Communes is
by shown plainly on the curve of growth. CHICAGO.

This city, on account of its large area in comparison with the population, has an average of only 6,430 inhabitants to the square mile, its area being 186 square
miles. In arriving at the population for 1894 , it is ecessary to use considerable judgment in deciding which census should be employed. There have been
estimates made of over $2,000,000$, but to be conservative the school census of 1894 is used, making the populaIn ascertaining the ratio of increase, different results he population, whether by the United States census or by that of the city. The increase from 1880 to 1890 by ng the United States census of 1890 with the school census of 1890, the ratio of increase per decade is 106
per cent. If, again, we compare the school census of
1884 with the school census of 1894, we have an increase of 150 per cent. per decade.
BERLIN.

The census of this city is taken every year and has 
been so taken since the year 1720 . Consequently, the almost any other city, as the poists in drawing the curve are wuch uearer together on the diagram. As
in the city of Paris diagram, so in that of Berlin, the effects of political and military disturbance in the 1756 to 1763 caused a decrease in the population. From 800 to 1810 , an entire decade, there is again a steady
decrease, and it was during this period that the battles of Hohenlinden, Jena, Auerstadt, Eylau and Fried-
land were fought with the French. By the peace of
Tilsit at the end of this period Prussialost one-half of her possessions and kept the other half under very harr conditions. In 1871 the King of Prussia was proclaimed Emperor of Germuny and Berlin became the
seat of the empire. From that time to the present the growth has been very rapid, the ratio of increase from 1883 to 1893 being 37 per cent.
In density Berlin stands next to Paris, the maximum ensity being 92,600 per square nile and the average density 67,612 , with an area of $24 \cdot 3$ square miles. VIENAa.

The accessible records of population of this city are very incomplete and the curve of population is made from a comparatively few dates. The authorities difthe garrison of the city is constantly changing vitiate the census records. PHILADELPHIA.

There is nothing particularly striking in regard to very regular. The density of population is very nearly like that of Chicago, being 8,091 per square wile on an

\begin{tabular}{c|c} 
ST. PETERsBurg. & $\begin{array}{c}\text { Certain important possible changes in conditions } \\
\text { need, however, to be considered in forecasting such } r\end{array}$ \\
The effect of the founder, Peter the Great, upon the
\end{tabular}

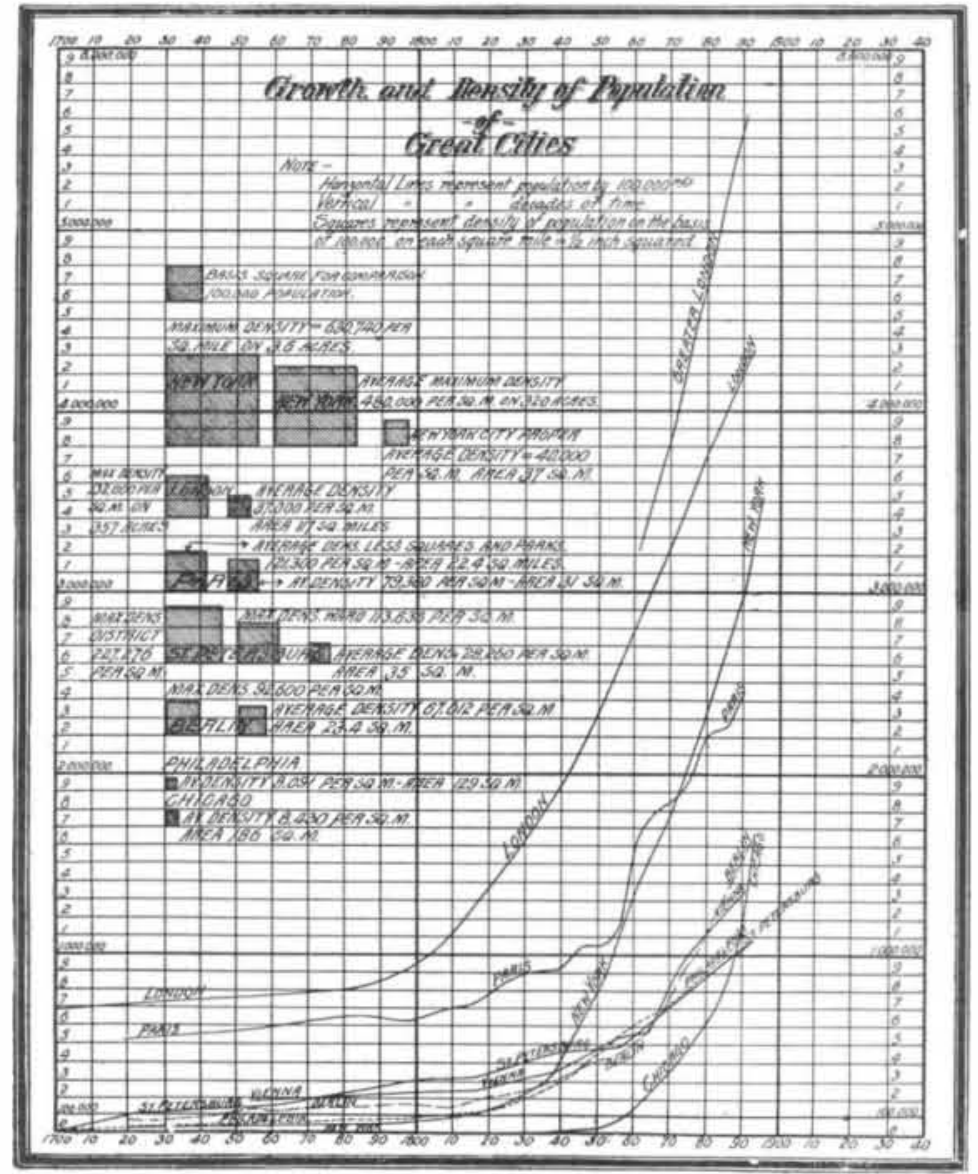

inception of this city and its growth during two de- methods of transportation may bring about, either cades is plainly seen at the origin of the curve. In in 1703 , compulsory means were employed to increase
the population to 100,000 during his reien. Under the population to 100,000 during his reien. Tnder der Catherine II, 1762 to 1796 , it reached nearly 300,000 . in that the city has a much larger population in th winter than in the summer, as is well known. The curve of growth includes this winter population and also the immediate suburbs, the object being to arrive at the metropolitan population. In reference to the 50.000 inhabitants, or at the rate of 113,636 per square mile, and the most thickly settled district in that ward age for the whole city on an area of 350 square miles is at the rate of 28,260 per square mile. PEKIN. or sparsely settled country. Second, the congestion or overcrowding of eity areas, making them too dense for
confort or health. These two conditions are already producing changes of magnitude in population. Lonion is an instance of these effects or of some others howing an increase, showed actual decrease in the last two census epochs.
It is difficult to predict now what change will tak place in New York during the succeeding decades by the contens of ated transportation changes ; such as the well's Island, the new. East River Bridge at Grand Street, the construction of one of the chartered bridges over the North River and probably the com 000,000 in new rapid, the expenditure of perhaps $\$ 60$ of electric locomotives and trolley lines for the present railroad locomotives, perhaps even the introduction of
high speed bicycle trains, fetc. As to Chicago, which is the phenomenal city of the world in respect to rapidity of growth, it may be safely assumed that its ratio of growth will continue with vo great diminution for two decades at least to come. Precedent, or the history rather of great cities, goes
to show this, and then its remarkably advantageou position commercially gives additional reason for this position commercially gives additional reason for this
belief. Berlin may also be expected to grow with great
rapidity for at least two decades more. As the seat of a new empire, it is still young, strong, vigorous and ambitious.
And in addition to all other reasons for the continuance in rapid growth of the above mentioned cities, there ency to tavitate to areat centers of population tend ency to gravitate to great centers of population whic Even with the above problematic conditions disturioing the future, there is sufficient ground on which to

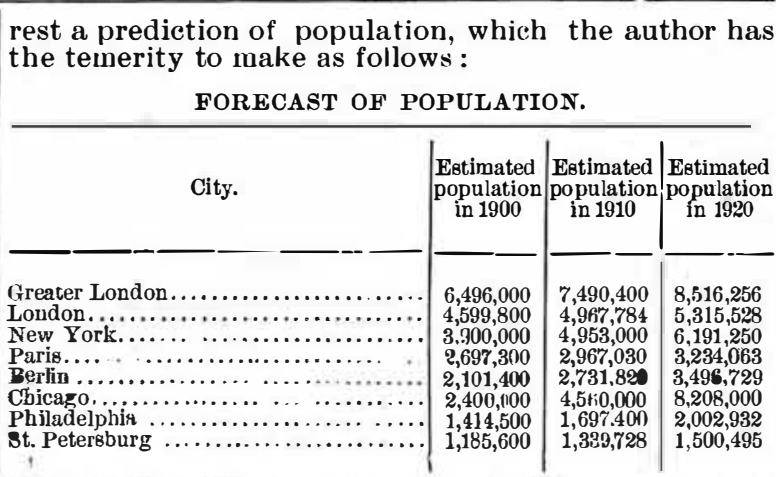

SELECTED FORMULAE

A Chemical Blotting Pad.-A cheap and excellent substitute for blotting paper may be extemporized as follows: Mix fourteen parts (by weight) of gypsum and two of potato flour, with sufficient water to produce a plastic paste. Pour or press into a suitable
mould. As soon as the mass has tecome hard and dry, mould. As soon as the mass has
it affords an admirable blotter.

Maple Sirup Substitute.--A farmer is accredited with the discovery of this maple sugar substitute. In his endeavors to render corn cobs utilizable for fodder he taste reminding of uple sirup and he now productis fictitious article, according to the newspapers, in the following manner: Twelve clean cobs were put in a gallon of water and boiled until soft. Then the juice was strained off and a gallon of dark brown suga solution added. This was boiled a little while, resulting in a fine quality of sirup hardly distinguishable

How to Transfer Newspaper Pictures. - The liquid to be used is made by dissolving one and one-hal drachms common yellow soap in one pint of hot water,
adding when nearly cold three and one-fourth fluid aunces spirit of turpentine, and shaking th oroughly ounces spirit of turpentine, and shaking thoroughly
together. This fluid is applied liberally to the surface of the printed matter with a soft brush or sponge (being careful not to smear the ink, which soon be-
comes softened), and allowed to soak for a few min-
utes utes; then well damp the plain paper on which the transfer is to be made, place it upon the engraving
and subject the whole. to moderate pressure for and subject the whole to moderate pressure for
about one minute. On separating them, a reversed about one winute. On separating them, a reversed
transfer will be found on the paper.-Alientown (Pa.) National Educator.

Snuffs for Hay Fever, Cold in the Head, etc. -The following fortum

\begin{tabular}{|c|c|c|c|}
\hline \multirow{2}{*}{\multicolumn{2}{|c|}{ 1. Cocaine hydrochlorate.......... }} & \multicolumn{2}{|c|}{${ }_{8.3}^{18}$ gramme } \\
\hline & & $\begin{array}{r}803 \\
300\end{array}$ & \\
\hline \multirow[t]{2}{*}{2.} & Co & 1.8 & \\
\hline & auth subnitrate. & 30. & \\
\hline \multirow[t]{3}{*}{3.} & Boric acid. & 20 & " \\
\hline & & & "6 \\
\hline & & & \\
\hline
\end{tabular}

Disinfection of Instruments. - (1) Sterilize coarse build ing sand by roasting. Fill a suitable vessel with this, and pour in a corrosive sublimate solution 4 per cent., or lysol 50 per cent., till the sand is thoroughly soaked; keep covered with a sterilized piece of pasteboard, pass
all instruments through this three or four times-offers all instruments through this three or four times-offers
simplicity, rapidity, absolute sterility, no injury to in simplicity, rapidity, absolute sterity, no injury to in -
struments.-Dr. A. W. Harlan. (2) A 10 per cent. solution of borogiycerine in water will sterilize forceps, broaches, and eutting instruments and leave then
without unpleasant odor. - Southern Dental Journal.

A Novel Magnesium Light.-Magnesinm powder is placed between two thin impenetrable sheets of paper wether. After drying a sheet of paper impregnated with potassium chlorate is placed on each side of th package. For an envelope a wider sheet of paper is pasted about the packet, so that the whole forms a thick leaf of paper, which can be cut with a scissors
into strips. To produce the light one of the strips i into strips. To produce the light one of the strips is
leld in a tongs and ignited, when it burns with a brilignt maguesium light. The magnesium paper preared in this way is claimed to be
ree from danger. - Am. Druggist.

Peerless Washing Fluid. -

Borax.... ground.

Concentrated lye ?

White (ivory) soal $\lfloor$ bar)

Oll of turpentine

Oil of sassafras

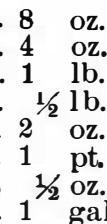

Bhave

Shave the soap and dissolve in the boiling water, add the soap bark aud borax, stirring them well to-
gether frequently for half a day, then strain and add the concentrated lye, oils and ammonia water, shaking used for each gallon of water in which the clothes are put to soak. - The Formulary.

A New Reagent for Bromine and Iodine.-J. H. Kastle has found, in his investigations of halogen derivative sulphonamide, which is easily obtained by passin chlorine into a solution of benzol sulphonanide in 10 ver cent soda solution. is an excellent reagent for dine and bromine. By adding it to the solution of an iodide or bromide in the presence of carbon disulphide the salts are decomposed and the iodine or bromine derivative of the anide is formed, which colors carbo mine itself. This reaction is quite as delicate as that $n$ which the halogen is detected by chlorine water and it has the advantage that the reagent remains unchanged on standing. 